\section{Revelando o vírus, ocultando pessoas: exames de monitoramento (CD4 e CVP) e relação médico-paciente no contexto da AIDS}

\author{
Disclosing the virus, hiding the patients: \\ follow-up tests (CD4 and VL) and the physician- \\ patient relationship in the AIDS setting
}

\author{
1 Instituto de Saúde Coletiva \\ Universidade Federal da \\ Bahia, Salvador, Brasil. \\ Correspondência \\ J. L. D. Guzmán \\ Instituto de Saúde Coletiva, \\ Universidade Federal da \\ Bahia. \\ Rua Augusto Vianna s/n, 2 o \\ andar, Salvador, $B A$ \\ 40110-060, Brasil. \\ jguzman@ufba.br
}

\section{Abstract}

The aim of this study is to discuss the meanings associated with the CD4 lymphocyte count and HIV plasma viral load (VL) for patients living with AIDS and the attending physicians, seeking to analyze the impacts of the increasing use of these tests in the treatment setting. A qualitative study was performed in two HIVIAIDS referral centers with participant observation and semistructured interviews with 27 patients living with AIDS and four physicians. Observation of the medical consultations showed that they are quick, objective, and centered on the CD4 and VL test results, thus reinforcing a hegemonic view of medical knowledge and a biomedical perspective that instrumentalizes their practice. For physicians and patients, the tests tend to reflect the "truth" on the patient's disease, to the detriment of the patient history and clinical examination, impacting the therapeutic relationship and leading to the physician's lack of attention to the patients' subjectivity. More than ever, there is a need to reclaim good clinical practice and acknowledge the subject's role in medical practice as a healing art.

CD4 Lymphocyte Count; Viral Load; HIV; Acquired Immunodeficiency Syndrome; PhysicianPatient Relations
Julio L. D. Guzmán 1

Jorge Alberto Bernstein Iriart 1

\section{Introdução}

A síndrome de imunodeficiência adquirida (AIDS) começou a fazer parte do cotidiano, na relação entre pacientes e profissionais de saúde no Brasil, a partir de sua identificação pelo Sistema de Vigilância Epidemiológica em 1982. Desde então, até junho de 2006, já foram notificados 433.067 casos de AIDS no país. Neste período, a tecnologia médica desenvolvida no combate à doença sofreu grande evolução. O vírus da imunodeficiência humana (HIV) foi identificado em 1984 e poucos anos depois surgiram os primeiros medicamentos anti-retrovirais (Zidovudina AZT). Em fins dos anos 80, aparece no cenário internacional o exame de carga viral plasmática (CVP) que começa a ser utilizado, primeiramente, para diagnóstico do estado de soropositividade em pacientes e, posteriormente, para monitoramento da doença. No início da década seguinte (1992), o Centers for Disease Control and Prevention (CDC) dos Estados Unidos passa a utilizar para reavaliar os critérios laboratoriais da imunodeficiência em estágios da infecção, um segundo exame: a contagem de linfócitos CD4. Foi, no entanto, com o advento do coquetel antiretroviral, em 1996, que o tratamento da AIDS torna-se mais efetivo aumentando a sobrevida e a qualidade de vida dos pacientes.

No Brasil, o Departamento de Imunologia da Fundação Oswaldo Cruz (FIOCRUZ) consegue isolar em 1987 o vírus HIV-1 e em 1990 o HIV-2, 
dando ao país condições de produzir seus próprios kits para o diagnóstico da doença, além de testar remédios e tentar desenvolver vacinas. $\mathrm{O}$ acesso universal à terapia anti-retroviral é efetivado a partir de 1991 com o uso da monoterapia com AZT. Em 1996, é introduzida a terapia antiretroviral de alta atividade (HAART - highly active antiretroviral therapy) com combinação de três medicamentos, e em 2006 já estavam disponíveis mais de 16 drogas para tratamento da AIDS. A disponibilidade da medicação anti-retroviral na política de acesso universal no Brasil gerou benefícios inequívocos, tanto no âmbito da assistência individual e qualidade de vida dos pacientes, quanto no âmbito coletivo, com a afirmação de uma política de inclusão social de indivíduos vivendo com HIV/AIDS e a redução da infeciosidade. Assim, esta política vem promovendo a diminuição do impacto da epidemia, a organização de serviços de saúde e o fomento às ações conjuntas com a sociedade civil para o enfrentamento da síndrome 1 .

A utilização das novas tecnologias médicas trouxe consigo uma mudança simbólica na forma de conceber a doença. Um novo olhar e uma renovada esperança para pacientes e familiares, calcada no advento tecnológico, contribuiu para que a AIDS, apesar de ainda incurável e letal, ganhasse contornos de uma doença viral crônica, na qual a aferição da imunodeficiência estaria representada pela contagem de linfócitos CD4 e o número de cópias virais (CVP) no sangue periférico $2,3,4$

Entre os anos de 1997 e 1998, os exames CD4 e CVP passaram a fazer parte da rotina da assistência aos pacientes vivendo com HIV/AIDS, tornando-se cada vez mais importantes na prática clínica. Sem deixar de reconhecer a importância destes exames na prática médica, é fundamental, todavia, que se enseje uma reflexão crítica sobre a forma como vêm sendo utilizados, seus significados para médicos e pacientes e sua repercussão na relação terapeuta-paciente. Vários autores apontam a assimetria existente na relação médico-paciente e como ela tem contribuído para um distanciamento entre os sujeitos, o que por sua vez se reflete no aumento do sofrimento dos soropositivos 5,6. Para Pfeutzenreiter 7, a tecnologia médica também vem contribuindo negativamente para a relação terapêutica, visto que reforça a racionalidade de uma medicina anátomo-fisiológica que se assenta no órgão doente e nos mecanismos fisiológicos que produziram o estado patológico em detrimento da subjetividade do paciente 8,9,10,11.

A questão que motivou este artigo foi justamente compreender os significados que os exames de monitoramento CD4 e CVP assumem para médicos e pacientes, buscando analisar os reflexos de sua crescente utilização na relação terapêutica. Parte-se do pressuposto que os exames estão ocupando cada vez mais o espaço terapêutico que se tecnifica em detrimento do diálogo e da escuta/toque dos pacientes por parte dos médicos. Pressupõe-se também que os exames de monitoramento não somente criam padrões de diagnóstico e terapêutica, como também contribuem para construção de identidades e tipologias, já que ao gerar uma classificação de "novos doentes ou meros portadores" influenciam os significados do adoecer e a auto-estima dos indivíduos vivendo com HIV/AIDS.

\section{A clínica e a tecnologia médica}

Segundo Foucault ${ }^{9}$, a medicina moderna nasceu a partir da ruptura com medicina teórica especulativa, centrada no relato do sintoma subjetivo sobre o mal-estar. Para o autor, essa ruptura estaria representada pela exploração do cadáver tornando possível visualizar a doença, os tecidos e as marcas corpóreas do sofrimento. Nesse processo, a medicina moderna - anátomo-fisiológica - tornar-se-ia científica, ao rejeitar a subjetividade de sua antecessora e direcionar-se ao invisível com relativa eficácia e objetividade. Assim, o médico moderno estaria sendo chamado a ver no interior dos corpos, "o sentir pelo órgão" em detrimento do relato subjetivo do paciente. Baseado em Foucault, Ribeiro 12 afirma que o médico tornou-se um tecnólogo do detalhe do órgão, tendo isso repercussão sobre o trabalho médico e sobre a representação no imaginário popular da doença e da atividade médica. Para este autor, funda-se, assim, a medicina dos "órgãos sofredores”, comportando um conjunto de procedimentos e um olhar específico: primeiramente, é imperativo "determinar qual é o órgão que sofre", em segundo lugar é necessário "explicar como o órgão tornou-se sofredor” e em terceiro lugar "indicar o que é preciso fazer para que deixe de sofrer". Cria-se, desse modo, uma lógica racional em que, com base no vínculo médico-tecnologia - "semiologia armada", a biomedicina adota do imaginário científico um modelo mecanicista para explicar o seu objeto, uma vez que parte-se da fragmentação das partes para entender seus mecanismos constitutivos e posteriormente reintegrá-los. A tecnologia "arma" a medicina na procura do "interior-objetivo" gerando uma dimensão vertical e reduzida do adoecer e, conseqüentemente, criando estados e classificações de doentes em indivíduos assintomáticos.

O homem moderno, em particular o médico, sente-se desafiado a desvelar a "verdade" im- 
pressa no corpo dos doentes. Na realização da atividade médica exploratória não se desvela a essência da técnica, mas sim seu caráter instrumental e antropológico. O homem-médico deve estar disposto ao desafio de enfrentar o oculto no corpo alheio. Eis aí a sua essência: "desencobrir” o real disposto nos corpos e explorá-los na possibilidade de encontrar a qualidade de vida e a longevidade e atribuir um sentido de corpo produtivo-social.

Para Heidegger 13, a essência da técnica moderna desafia o homem para a composição, como destino de um "desencobrimento". A técnica, neste ponto, nos toma, apodera-se de nós e nos torna dependentes e, segundo Heidegger, aí residiria o perigo. "O destino do desencobrimento não é, em si mesmo, um perigo qualquer, mas o perigo" 13 (p. 30). Os exames CVP e CD4 não desvelam apenas um embate entre o sistema imunológico e o vírus da AIDS, adquirindo outros significados e finalidades segundo o contexto de seu uso. Eles podem predizer a vinda da morte, a piora da enfermidade, o descaso do paciente com a terapêutica, a eficácia do tratamento ou o momento de cuidar. É, sobretudo, nesse exato momento do cuidado, que a interpelação da técnica nos substitui em nossas decisões e ações. Substituinos naquilo que mais nos caracteriza em nossa humanidade, segundo Heidegger 13, que é o sermos pastores do ser, cuidadores do ser. Como a técnica estipula o modo de cuidar, ela nos rouba nossa condição: cuida por nós 13,14.

Conforme Maia 11, o que é realmente inquietante na contemporaneidade não é que o nosso mundo se torne um mundo completamente técnico guiado pelas máquinas, mas antes que o homem não esteja preparado para essa transformação. Como conseqüência, o pensamento calculador tomaria o centro das atenções tornando o homem um servo a serviço da técnica. O perigo da dependência de objetos tecnológicos estaria no fato de tornar-nos seus "escravos". É possível, contudo, utilizarmos os objetos tecnológicos para nos servirmos deles como auxiliares/ complementares sem nos tornarmos escravos da tecnologia na realização da atenção/assistência/cuidado. Podemos dizer "sim" à utilização da técnica, mas também "não" ao fato da técnica monopolizar, desunir e violar o nosso ser. A questão central é a de o homem não deixar que a técnica atinja o que temos de mais íntimo e de mais próximo.

\section{Métodos}

Foi realizado um estudo qualitativo no qual foram combinadas duas técnicas de pesquisa social: a observação participante, com registro em diário de campo, e as entrevistas semi-estruturadas. $\mathrm{O}$ estudo foi realizado em dois centros de referência em DST/HIV/AIDS na Bahia, Brasil. Ao todo foram entrevistados em profundidade 27 pacientes que vivem com AIDS e são atendidos nos dois centros, assim como quatro médicos de assistência. Procurou-se priorizar na seleção dos informantes, mediante indicações da equipe de saúde, os pacientes que possuíam maior experiência no acompanhamento laboratorial para monitoramento da AIDS. Em alguns casos, os próprios entrevistados indicaram outros pacientes para as entrevistas. Os pacientes entrevistados tinham entre 22 e 55 anos, sendo 15 deles do sexo masculino. A média de anos vivendo com AIDS foi de 13 anos. A maior parte tinha baixa escolaridade com Ensino Fundamental incompleto. Somente sete pacientes tinham completado o Ensino Médio, sendo três deles com nível superior. As entrevistas buscaram inquirir os sentidos, significados e práticas associados aos exames CD4 e carga viral e sua interface com a relação médico-paciente. As entrevistas foram gravadas em meio eletrônico e transcritas.

O trabalho de campo se desenvolveu durante seis meses e a observação participante, realizada de forma descontínua (em visitas semanais em diferentes turnos e horários), permitiu acompanhar a rotina de trabalho nos dois centros de referência, possibilitando confrontar discursos e práticas de médicos e pacientes. Foram observadas 32 consultas médicas e a rotina da sala de espera nos centros de referência. Para a observação das consultas, médicos e pacientes foram consultados previamente e consentiram a permanência do investigador na sala.

Para a análise do material produzido, ancoramo-nos no movimento da etnografia contemporânea e privilegiamos uma análise interpretativa centrada na compreensão dos significados e práticas dos sujeitos em relação à tecnologia médica no contexto da AIDS. Foi realizada a leitura de todas as entrevistas e observações registradas em diários de campo buscando identificar os temas mais salientes, as figuras de linguagem utilizadas, os contrastes e recorrências nos dados produzidos. O programa Nudist versão NVivo (QRS International Pty, Doncaster, Austrália) foi utilizado para a codificação e organização dos dados das entrevistas e observações com base nas categorias analíticas (significados dos exames CD4/CVP para médicos e pacientes, significados das consultas médicas) e posterior criação 
de subcategorias, incluindo as categorias nativas ou êmicas.

O projeto de pesquisa foi aprovado no Conselho de Ética em Pesquisa do Instituto de Saúde Coletiva, Universidade Federal da Bahia, e todos os participantes da pesquisa consentiram voluntariamente em dar os seus depoimentos ou permitir observações, com garantias do sigilo de suas identidades e salvaguarda de sua participação voluntária e desinteressada. Todos os participantes da pesquisa assinaram consentimento informado em acordo com as premissas éticas da pesquisa com seres humanos previstas na Resolução $n^{o}$. 196/96 do Conselho Nacional de Saúde.

\section{Resultados}

\section{A consulta médica}

A observação das consultas médicas nos dois centros de referência evidenciou o papel central que os exames CD4 e CVP desempenham na relação terapeuta-paciente com AIDS. De maneira geral, o resultado dos exames ocupou a maior parte do tempo total da consulta que, em média, variou entre 5 e 8 minutos. O tempo de espera pelo início da consulta, porém, situou-se entre 45 e 90 minutos. Durante as reconsultas, os resultados dos exames eram objeto da atenção dos médicos logo no início da consulta. Muitas vezes, os próprios pacientes, logo após adentrar a sala, já perguntavam aos profissionais pelos resultados dos exames. Nesse momento, quando os resultados eram positivos ou satisfatórios, a consulta tornava-se objetiva e focalizada nos resultados, e raramente o médico realizava uma anamnese ou um exame físico.

Observou-se que poucas vezes os médicos demonstravam interesse em ler os relatórios dos outros profissionais contidos no prontuário ou abordavam aspectos subjetivos da vida cotidiana dos pacientes. Quando aspectos subjetivos eram trazidos à consulta pelos pacientes, os médicos procuravam limitar a discussão desconsiderando-os ou rebatendo-os com base nos resultados dos exames. Entretanto, nos casos em que o resultado dos exames mostrava sinais de recaída ou falha viral ou imunológica, a consulta tomava outra direção, na qual os médicos buscavam desvelar uma atitude desviante por parte do paciente sobre o cumprimento das orientações médicas, especialmente a não-aderência ao tratamento anti-retroviral. Os resultados dos exames eram assim utilizados na sua capacidade reveladora de avaliar o cumprimento/seguimento das orientações médicas para o cuidado esperado do paciente ante sua doença.

\section{A tecnologia médica como espelho revelador da doença}

Para os pacientes entrevistados, os exames CD4 e CVP funcionam como instrumentos que lhes permitem ver a doença de uma forma mais clara e concreta. A concretização é representada pela "metáfora bélica", muito recorrente nos discursos, e que concebe a doença como um "enfrentamento militar" de agentes agressores - HIV e os soldados de defesa - células brancas linfocitárias. Os exames teriam o poder de revelar o vírus, que de outra forma estaria invisível e de mostrar como se processa tal "guerra" no interior do organismo.

“Os meus soldadinhos de defesa está com o exército maior do que o exército inimigo, que é o vírus da AIDS. Então, pra isso que serve esse exame, pra poder o profissional diferenciar o balanceamento entre o vírus do HIV e minhas células de defesa" (E-10).

" $[\mathrm{O}$ exame CD4] diz como o vírus destrói o corpo. É como se fosse os pequenos soldadinhos (...) eles vão destruindo os glóbulos, ele vai tirando da gente toda nossa defesa, ai o exame diz isso para mim, da destruição, entendeu? (...) [O exame CVP] diz se eles [os vírus] estão congelados ou não..." (E-3).

Segundo um entrevistado, a doença oportunista, como parte de uma constelação sindrômica da AIDS, se encontra escondida em determinados reservatórios no interior do corpo. A doença sai do seu campo de batalha - o sangue - para se esconder na profundeza do corpo, onde os soldados - células de defesa - não poderão alcançá-la. O esconderijo pode estar em qualquer parte, mas, na visão do entrevistado, como o profissional tem conhecimento a respeito da doença, ele poderá encontrar as armas (os exames complexos) para descobri-los. O exame, enquanto arma na luta pela identificação e rastreamento da doença pelo corpo, complementa a metáfora bélica acima citada.

“Ele [o paciente] pode tá com uma [doença] oportunista escondida. Sabe que nosso organismo, ele tem diversos esconderijos e pra descobrir o esconderijo faz-se necessário de altos exames, né? Têm exames aí de alta complexidade. Exames mais eficazes que possam identificar esses elementos que causam esse tipo de infecções, dessas doenças" (E-10).

O exame ganha aqui uma construção simbólica: inimigo do vírus e aliado do paciente por sua capacidade de informá-lo sobre a sua doença. O "paciente armado" procura então enfrentar o vírus, sendo ambos inimigos do último (o paciente e os exames), como também o seria o linfócito CD4. Mais do que isso, no entanto, para os pa- 
cientes entrevistados os exames têm o poder de revelar a "verdade" sobre a doença do indivíduo, muito mais que sua experiência subjetiva da doença.

"O exame que vai me dizer se eu estou bem, $e$ se eu estou mal. Claro que eu vou preferir que o exame me diga que eu estou bem. Mas ao mesmo tempo se o exame me diz que eu estou mal, ele tá sendo um amigo pra mim. (...) Então o exame é um identificador. Sendo o exame meu amigo, e o vírus meu inimigo" (E-10).

"Eu fazendo esse exame, eu vou ficar sabendo se eu tô bem ou se eu tô mal. É essa a utilidade, que o exame vai comprovar se eu tô bem ou tô mal, é ele que vai dizer como é que está a minha saúde (E-2)".

"O exameé fundamental. Se não tiver nenhum exame, como saber como é que você tá?” (E-16).

Os resultados positivos dos exames permitem ao paciente se sentir seguro, pois trazem concretude a sua percepção de bem-estar, que de outra forma poderia ser ilusória ou fugaz.

"Então esses exames dá muita segurança, é a melhor parte. (...) No sentido que você acha que você tá bem, que os exames tá mostrando ali que você tá bem" (E-22).

Os exames, por sua capacidade de perscrutar as profundezas do corpo, permitem ao médico revelar a "essência da doença", ao contrário do exame físico e da anamnese que revelam apenas sua "aparência". Sem os exames, os médicos ficam sem ação em face da doença.

"Interessante é minha essência e não minha aparência. Mas acho que médico nenhum dá nada pela aparência, as noticias que eles passam são todas pela essência, através de exames, se eles não tiverem exames eles não podem saber (...). É o essencial, sem isso ele não consegue quase nada" (E-21).

"Eu acho que o exame vai profundo né? Você faz exame de sangue, você leva lá, no outro dia para a máquina e você tá sabendo o que você tem (...). O médico ele estuda por fora praticamente. E a máquina já vai como que saiu de dentro de você pra fora pra ela detectar (...) o exame me dá confiança em, em que eu tenha certeza de que, de que eu vou saber do que é que eu tenho pra que eu possa me tratar e ficar curada" (E-18).

A construção da doença localizada no sangue e nas profundezas do corpo reforça a lógica de que é no seu estudo minucioso que os médicos, por intermédio dos exames, procuram os caminhos para o acompanhamento e monitoramento dos pacientes. O exame permite produzir uma informação que vai além da experiência médica. Sua concretude está na capacidade de explorar essa "essência", de pesquisar o organismo. O resultado dessa pesquisa seria o que determinaria a conduta médica, independentemente do discurso subjetivo dos pacientes. Sem o resultado dos exames, o médico estaria impossibilitado de trabalhar porque não seria possível embasar-se somente em "dados fictícios".

O ponto de vista dos médicos sobre os exames CVP e CD4 apresenta muitas semelhanças com a perspectiva dos pacientes. Também para os médicos, os exames refletem a "verdade" sobre a doença do paciente.

"A gente tem acesso a uma boa quantidade de exames, de carga viral e CD4 que espelha muito melhor o atual problema do doente" (Médico).

Segundo os médicos entrevistados, a introdução dos exames CD4 e CVP na rotina de acompanhamento dos pacientes vivendo com HIV/AIDS representou um grande avanço no entendimento da doença. As novas tecnologias melhoraram o atendimento, ao possibilitar aos profissionais diagnosticar com mais precisão as doenças oportunistas. Por conseguinte, uma intervenção precoce permite uma melhora da qualidade de vida dos pacientes e auxilia a evitar a morte como um evento prematuro.

"Melhorou o diagnóstico, se tornou bem mais fácil, menos complicado, e melhorou o tratamento né? A gente aprendeu a diagnosticar mais cedo também as doenças oportunistas (...), com a facilidade que a gente tem hoje pra dosar CD4, dosar carga viral. Antigamente a gente não tinha nada disso. Era tudo no olho clínico (...). A gente com o CD4 tem segurança, se sente seguro pra dizer ao paciente 'você tá bem, você não vai ter infecção' ou dizer a ele 'você tá ruim, você tá correndo sério risco"' (Médico).

Enquanto a tecnologia possibilitou enxergar melhor a doença, ela também limitou a necessidade de utilizar o olho clínico, subjetivo e percebido como impreciso, assim como contribuiu para, da forma como está sendo utilizada, relegar ao segundo plano a atenção à subjetividade do paciente. Nas falas dos médicos, a substituição do olho clínico pelos exames CD4 e CVP termina por transferir a estes a capacidade/autonomia para indicar a conduta médica.

"Primeiro o exame, que se eu não tenho o resultado CD4, eu não tenho resultado de CD8, eu não tenho carga viral, eu não fiz a avaliação do paciente para ver se o paciente tem doença constitucional, tem AIDS clínica, eu não tenho outros exames, que vão me dar subsídios para iniciar a terapia anti-retroviral" (Médico).

É a tecnologia, aqui representada pelos exames de monitoramento, quem revela a "essência” da doença que se reduz cada vez mais a sua dimensão fisiopatológica. Recorrendo aos conceitos de disease e illness desenvolvidos pelo médico e antropólogo Kleinman 15, segundo o qual 
a disease representa o processo fisiopatológico e a illness diz respeito à experiência da enfermidade pelo paciente, englobando sua dimensão subjetiva e os significados que adquire em seu contexto sócio-cultural, podemos afirmar que a atenção dos médicos está voltada para a disea$s e$, desconsiderando a illness e esquecendo que a enfermidade não se esgota em sua dimensão fisiopatológica.

\section{A consulta do ponto de vista de médicos e pacientes}

Apesar da grande importância atribuída pelos pacientes aos exames CD4 e CVP, a consulta rápida e focada em dados objetivos, com limitações sobre as orientações e espaço limitado para o exercício de sua autonomia foi muito criticada, sendo interpretada como falta de interesse ou cuidado do profissional para com a doença e o bem-estar dos seus pacientes. Portanto, aos sentir-se pouco observado, ouvido e examinado, o paciente tecia uma relação impessoal e sentia-se desprovido de apoio para enfrentar o seu malestar e a sociedade.

Para os pacientes, a confiança aparece como fundamental na relação terapêutica, e a consulta rápida e objetiva representa uma barreira para a sua construção no espaço terapêutico. A confiança representa para os pacientes a possibilidade de abrir-se, exteriorizar os seus sentimentos para conversar sobre aspectos íntimos do cotidiano.

"Não me habituei direito com o Dr. assim né, não pela pessoa dele mas a confiança, né? É com o tempo que se adquire confiança com as pessoas, né? Eu ainda não adquiri essa confiança nele. Assim, ele ainda não conseguiu me cativar, pra eu ter esse relacionamento um pouco mais aberto" (E-7).

"Conversar com seu médico, o importante também é isso, é se abrir com o médico" (E-8).

"É isso o paciente ter liberdade de falar tudo para o médico. [Ele] ouvir o que tenho para falar, depois ele se pronunciar, entendeu? E chegar a um acordo os dois, não só ele falar o que tá certo e tá errado. Ouvir o paciente também" (E-25).

Do ponto de vista dos médicos entrevistados, a conversa franca apresenta-se como a melhor estratégia para abordar o paciente na consulta. Os médicos reconhecem, todavia, a sua dificuldade em abordar o paciente que demanda por informação e, sobretudo, lidar com questões da subjetividade dos pacientes que, por vezes, afloram durante as consultas. Uma das estratégias utilizadas é a de evitar, na conversa, caracterizar a AIDS como uma doença incurável e mortal. Busca-se, ao contrário, mostrar a AIDS como uma doença com cara nova, uma doença crônica.
"A gente tem que enfrentar, eu costumo enfrentar, chegar no paciente, olhar nos olhos dele e dizer o que é que está acontecendo. Depois de muita conversa, explicar que a doença não é mais isso, fazer aquele efeito vaselina que a gente tem que fazer, e fazer com que o paciente enfrente o melhor possível isso de frente e que não fuja, não tente ser uma avestruz, né?" (Médico).

"Oh, o que eu faço como eu tenho uma formação muito pragmática... é sempre assim em linha reta, né? É, eu vejo isso da seguinte forma, eu procuro dar as informações que eu tenho da melhor forma, assim mais tranqüilo, com mais cuidado possível, no sentido de desmiudar aquelas informações e distribuindo essas informações no decorrer das próximas visitas. Agora eu sempre pego um apoio com uma psicóloga que nós temos aqui, quando a coisa... você vê assim que o paciente às vezes tá meio choroso, ou precisa até do apoio da família" (Médico).

Falar da doença representa, no entanto, um desafio para os médicos que buscam o apoio da equipe multiprofissional. Dois dos médicos entrevistados afirmaram que outros profissionais, com outra formação, poderiam ajudar mais do que eles mesmos e um dos entrevistados limita a atuação do médico a assuntos técnicos considerando que outros assuntos devem ser tratados com outros membros da equipe mais capacitados.

"Eu acho que esse assunto [a abordagem ao paciente com HIV/AIDS] tem que ser tratado (...). E o médico, a enfermeira, o psicólogo, o psiquiatra cada um dentro da sua área, tem que ver algumas coisas fora da sua área, você tem que dar um apoio, um apoio social, entendeu? É a questão da ligação médico-paciente que o profissional tem. $O$ cara [médico] trata do assunto técnico, mas do assunto social ele não tem habilidade pra tratar, ou não quer também tratar. Você não quer tratar e o paciente também não tem uma abertura boa pra isso. Então o profissional, o paciente tem que procurar dentro dessa equipe quem é que ele poderia ter uma relação melhor de contato. É ele quem vai ter esse entendimento, vai conhecer todo mundo. Oh, aquele cara lá vou me dar melhor com ele, que ele é um cara bacana comigo" (Médico).

\section{Discussão}

A observação das consultas médicas mostrou que elas são rápidas, objetivas e centradas no resultado dos exames CD4 e CVP, fato que reforça uma visão hegemônica do saber médico e uma visão biomédica da medicina que instrumentaliza a sua prática. Verificou-se também que a escuta do paciente e o reconhecimento e valorização 
da sua subjetividade não transparece nas consultas como um elemento fundamental na atenção/assistência/cuidado aos pacientes vivendo com HIV/AIDS.

Britto \& Alves 16 propõem a classificação das consultas atendendo ao tempo dispensado pelo profissional, a linguagem utilizada e o exercício da autonomia do paciente em três modelos: modelo 1 - quando a consulta rege-se segundo as necessidades do paciente, é estruturada e com exame físico completo, há predomínio de perguntas abertas e é reservado um espaço para a orientação, há investigação sobre parceiros sexuais e orientação do uso da camisinha; modelo 2 - consulta rápida, o exame físico depende da necessidade evidente do paciente, o médico centra-se em orientações formais e encaminha exames e atendimento com outros especialistas e; modelo 3 - consulta ultra-rápida, centrada na investigação sobre o uso da medicação, exame físico como exceção, perguntas fechadas e respostas do tipo sim ou não. Nos centros observados neste estudo, predominaram as consultas categorizadas como modelo 2 e poucas vezes observou-se consultas do modelo 1. A consulta modelo 2 fazia parte majoritária das primeiras consultas e a modelo 3 era a que mais caracterizava a consulta de retorno. No segundo centro de referência, as consultas modelo 1 eram mais utilizadas no primeiro contato com o paciente, porém, durante o retorno observamos também a prática regular de uma consulta tipo modelo 3, particularmente com pacientes mais assíduos ou conhecidos pelo programa.

Segundo Nogueira-Martins 17, o processo de desenvolvimento tecnológico no campo da saúde tem deslocado o lugar da singularidade do paciente - emoções, crenças e valores - pela doença, sendo esta o objeto da ação e único saber reconhecido cientificamente, de forma que podemos afirmar que a assistência à saúde se desumanizou. Para Rosengarten et al. 4, nós assistimos hoje a uma tecnificação da assistência a pacientes portadores de HIV/AIDS que se manifesta na mudança no estilo dos médicos em desenvolver a consulta e em uma redução do tempo dedicado ao diálogo com o paciente. Segundo os autores, a introdução da tecnologia na AIDS mudou o perfil do profissional. Os médicos passaram a assumir o seu papel como avaliadores de risco devido ao fato de prescreverem medicamentos orientados pelos exames, deixando de lado sua figura como profissional que oferece cuidados à saúde, healer ou carer da saúde. Os profissionais mostram-se mais interessados em abordar o paciente como um protocolo logístico baseado em evidências, do que a se engajar nas questões do dia-a-dia destes sujeitos. Desse modo, para os médicos, diante de exames satisfatórios que mostravam que havia uma melhora clínica-laboratorial, os sintomas, medos, e sentimentos dos pacientes ocupavam um lugar secundário, não havendo necessidade de se preocupar com outras coisas que pertenciam ao campo subjetivo/psíquico.

A tecnologia permite um olhar ao interior do corpo, ao tempo que medicaliza a medicina no sentido de descobrir estados pré-mórbidos, embora úteis para a prática 4 . Logo, embora o paciente esteja se sentindo bem, os exames CD4 e CVP podem indicar que ele está doente e que é o momento de começar a terapia anti-retroviral. Em outras palavras, o paciente não se sente doente ou não tem illness, a experiência subjetiva da enfermidade. Os exames, contudo, revelam a disease (processo fisiopatológico), e a avaliação subjetiva do paciente é substituída por este novo olhar. Nesse sentido, a sua introdução instrumentaliza o olhar médico e o cientifica 7,18,19.

No caso da AIDS, os exames CD4 e CVP adquirem também um papel de controle do médico sobre a conduta dos pacientes ao apontar aqueles que seguem e os que não seguem as prescrições médicas. É importante frisar que a associação de falha terapêutica a "mau comportamento" do paciente perante o cuidado com a doença nem sempre é linear, uma vez que se discutem hoje outras possibilidades biomédicas de fracasso terapêutico.

Como nos lembra Heidegger ${ }^{13}$, o perigo da técnica não está nela própria, senão na relação do homem com ela. O paciente está na frente do médico, mas não a avaliação da sua "verdade". A verdade mora, para o médico, no campo da ciência, dos exames e não no mundo da arte pela sua imprecisão. Sendo solicitado para tomar uma conduta sem os exames, ela poderia ser prejudicial ao paciente. $\mathrm{O}$ homem, sendo convidado a interiorizar a tecnologia, acaba sendo possuído por ela. A própria rotina da consulta médica é redefinida tornando-se centrada e pautada pelos exames que deveriam ser complementares. Neste sentido, o médico sente-se impossibilitado de lidar com o acompanhamento de pacientes que vivem com HIV/AIDS sem poder contar com os exames, tal o grau de incerteza que o olhar clínico provoca. Ancorando-nos em Maia 11, no mundo da AIDS, corre-se o perigo de torná-lo um mundo completamente técnico. Não estando o homem preparado para essa transformação, limitaria o valor do sujeito quando o ideal seria que este (o sujeito com toda a sua experiência subjetiva) se somasse à "verdade da ciência".

Segundo Heidegger 13, a possibilidade da técnica moderna de desencobrir o oculto nos corpos possibilita um olhar ao interior - a essência - como foi dito por um dos pacientes entre- 
vistados. A metáfora militar, analisada nos trabalhos de Sontang 20; Oltramari 21 e Herzlich \& Pierret 22, contribuem para essa concretude e representam uma reinterpretação do discurso médico porque ambos se utilizam dessas imagens simbólicas para explicar os mecanismos causais da doença. Desta forma, o número impresso no resultado dos exames gera toda uma constelação de significados pela representação da AIDS como metáfora, do papel/utilidade dos exames e da ressignificação do discurso médico, contidos na dimensão sócio-cultural e histórica que modela seu simbolismo. A ressignificação da utilidade da tecnologia médica para os pacientes reforça as transformações da medicina contemporânea que privilegia o olhar da ciência sobre o paciente e instrumentaliza uma prática segmentada sobre o corpo e o cuidado em saúde que caracteriza "a crise de confiança" sobre a figura do médico 23.

Assim sendo, há uma necessidade de retomada da prática da boa clínica e do reconhecimento do papel do sujeito da prática da arte da medicina. Parece-nos inconseqüente que a confiança no profissional seja relegada a um segundo plano pelo resultado de uma máquina. $\mathrm{O}$ alcance às expectativas de pacientes e profissionais sobre o tratamento e o cuidado deve estar aberto a um diálogo e a um partilhar de juízos e deci- sões. Superar a crise, também seria superar esta relação polarizada, paradoxalmente, pelo avanço de uma medicina tecnológica centrada no dado objetivo ${ }^{23,24}$. Não está em debate a potencialidade da tecnologia em mostrar uma doença visível em um corpo que nega a se sentir doente, como também evidenciar antecipadamente a possibilidade de uma complicação. O ponto central de nossa discussão é o prejuízo que o exercício de uma medicina biomédica altamente armada tecnologicamente desempenha para um relacionamento carregado de desconfiança entre médicos e pacientes.

A relação de confiança se dá no princípio da solidariedade, do cuidado com o outro, da atenção individualizada, na construção de espaços de escuta/toque onde se procura alívio para a dor e os sofrimentos mais imediatos. Em razão disso, concorda-se sobre a necessidade de um trabalho em saúde que venha resgatar a integralidade do próprio homem com práticas de assistência humanizadas. Cabe aos médicos repensar a sua prática e retomar o lugar do sujeito. É fundamental procurar na relação com o paciente as ferramentas imprescindíveis para o exercício de uma medicina, na morada da alteridade/confiança, que priorize uma atenção/assistência/cuidado em todos os sentidos, rumo à saúde.

\section{Resumo}

O objetivo deste artigo é discutir os significados as sociados aos exames de contagem de linfócitos CD4 e quantificação da carga viral plasmática do HIV (CVP) para pacientes vivendo com AIDS e médicos da atenção, buscando analisar os reflexos de sua crescente utilização na relação terapêutica. Foi realizado um estudo qualitativo em dois centros de referência em HIVIAIDS com observação participante e entrevistas semi-estruturadas com 27 pacientes vivendo com AIDS e quatro médicos. A observação das consultas médicas mostrou que elas são rápidas, objetivas e centradas no resultado dos exames CD4 e CVP, o que reforça uma visão hegemônica do saber médico e uma perspectiva biomédica que instrumentaliza a sua prática. Para médicos e pacientes, os exames passam a refletir a "verdade" sobre a doença do paciente em detrimento da anamnese e do exame clínico, fato que se reflete na relação terapêutica e na desatenção por parte dos médicos à subjetividade dos pacientes. Mais do que nunca há necessidade da retomada da prática da boa clínica e do reconhecimento do papel do sujeito na prática da medicina como arte de curar.

Contagem de Linfócito CD4; Carga Viral; HIV; Síndrome de Imunodeficiência Adquirida; Relações MédicoPaciente 


\section{Colaboradores}

J. L. D. Guzmán e J. A. B. Iriart participaram igualmente da elaboração do artigo.

\section{Referências}

1. Grangeiro A, Teixeira L, Bastos FI, Teixeira P. Sustentabilidade da política de acesso a medicamentos anti-retrovirais no Brasil. Rev Saúde Pública 2006; 40 Supp 1:60-9.

2. Secretaria de Vigilância em Saúde, Ministério da Saúde. Programa Nacional de DST e AIDS. Consenso: recomendações para terapia anti-retroviral em adultos e adolescentes infectados pelo HIV. Brasília: Ministério da Saúde; 2006.

3. Cunha CC. Revelando vozes, desvendando olhares: os significados vozes do tratamento por HIV/AIDS [Dissertação de Mestrado]. Rio de Janeiro: Escola Nacional de Saúde Pública, Fundação Osvaldo Cruz; 2004.

4. Rosengarten R, Imrie J, Flowers P, Davis MD, Hart GJ. After the euphoria: HIV medical technologies from the perspective of their prescribes. Sociol Health Illn 2004; 26:575-96.

5. Caprara A, Rodrigues J. A relação assimétrica na relação médico-paciente: repensando o vínculo terapêutico. Ciênc Saúde Coletiva 2004; 9:139-46.

6. Robert F. The interactional construction of the asymmetry. Sociol Q 2000; 14:151-70.

7. Pfeutzenreiter MR. A ruptura entre o conhecimento popular e o científico em saúde. Ensaio - Pesquisa em Educação em Ciências 2001; 3:1-15.

8. Camargo Jr. KR. A biomedicina. Physis (Rio J.) 2005; 15 Suppl:177-201.

9. Foucault M. O nascimento da clínica. 6a Ed. Rio de Janeiro: Editora Forense Universitária; 2004.

10. Luz MT. Cultura contemporânea e medicinas alternativas: novos paradigmas em saúde no fim do século XX. Physis (Rio J.) 2005; 15 Supp:145-76.

11. Maia I. Sobre a serenidade em Martin Heidegger http://consciencia.org/contemporanea/heidegge risabel.shtml (acessado em 02/Nov/2004).

12. Ribeiro HP. Hospital: história e crise. São Paulo: Cortez Editora; 1993.

13. Heidegger M. Ensaios e conferências. Petrópolis: Editora Vozes; 2001.
14. Critelli DM. Martin Heidegger e a essência da técnica. Revista Margem 2002; 16:83-9.

15. Kleinman A. Patients and healers in the context of culture. Berkeley: University of California Press; 1980.

16. Britto e Alves MTSS. Avaliação da assistência ambulatorial a pessoas vivendo com HIV/AIDS no Sistema Único de Saúde: a situação no Maranhão [Tese de Doutorado]. São Paulo: Faculdade de Medicina, Universidade de São Paulo; 2003.

17. Nogueira-Martins MCF. Humanização na saúde: Programa Nacional de Humanização da Assistência Hospitalar (PNHAH). http://www.humaniza. org.br (acessado em10/Set/2006).

18. Campos GWS. Reforma da reforma: repensando da saúde. 2a Ed. São Paulo: Editora Hucitec; 1997.

19. Schraiber LB. O médico e seu trabalho: limites da liberdade. São Paulo: Editora Hucitec; 1993.

20. Sontag S. AIDS e suas metáforas. São Paulo: Editora Companhia das Letras; 1989.

21. Oltramari LC. Um esboço sobre as representações sociais da AIDS nos estudos produzidos no Brasil. (Cadernos de Pesquisa Interdisciplinar em Ciências Humanas, 45). http://www.cfh.ufsc.br/ dich/ TextoCaderno45.pdf (acessado em 15/Jan/2007).

22. Herzlich C, Pierret J. Uma doença no espaço público: a AIDS em seis jornais franceses. Physis (Rio J.) 2005; 15 Supp:71-101.

23. Schraiber LB. No encontro da técnica com a ética: o exercício de julgar e decidir no cotidiano do trabalho em medicina. Interface Comun Saúde Educ 1997; 1:123-40.

24. Ayres JRCM. Cuidado e reconstrução das práticas de saúde. Interface Comun Saúde Educ 2004; 8:73-91.

\section{Recebido em 30/Jun/2008}

Versão final reapresentada em 19/Nov/2008 Aprovado em 17/Dez/2008 